\title{
LETTER
}

\section{Patients with hematologic malignancies have many reasons to die during extracorporeal membrane oxygenation}

\author{
Matthieu Schmidt, Daniel Brodie and Alain Combes \\ See related research by Wohlfarth et al., http://ccforum.com/content/18/1/R20
}

We read with great interest the article by Wohlfarth and colleagues [1] regarding the use of extracorporeal membrane oxygenation (ECMO) in 14 adult patients with hematological malignancies. We would like to highlight two main points.

First, the authors focused their report and their discussion on bleeding complications and anticoagulation management in this high-risk population. Although we concede that it is a serious concern in these patients, it is not the only one. ECMO support is associated with nosocomial infections [2,3]. Impairment of cellular immunity, cytopenia and chemotherapy (CT) may further increase the risks of infection and may dissuade clinicians from using ECMO in these patients. Developing new strategies that aim to limit nosocomial infections is crucial to improving outcomes in this population. ECMO in awake, non-intubated, spontan- eously breathing patients with acute respiratory distress syndrome, to avoid mechanical ventilation and its related adverse events, is a potentially promising application [4]. Thus, in our opinion, it would also be important to provide a thorough description of nosocomial infections that might have occurred in these 14 patients.

Second, the authors reported that 5 of 14 patients initially received $\mathrm{CT}$ while receiving ECMO. The pharmacokinetics of many of the medications administered to patients receiving ECMO are complex [5] and, to date, there are very limited data to guide our daily practice. Therefore, clinicians must be aware that providing CT to patients receiving ECMO is a potential gamble, which risks worsening patient outcomes due to ineffective drug regimens. CT during ECMO should be restricted to those cases where postponing therapy is not an option.

\section{Authors' response}

Philipp Wohlfarth, Thomas Staudinger and Peter Schellongowski

We thank the authors for their thoughtful considerations. Eight of the ten cases of pneumonia leading to ECMO were hospital-acquired. However, the number of proven infections during the ICU stay was low. Of 110 cultures (broncho-alveolar lavage, blood, urine, catheters, stool, pleural/pericardial effusion, lung biopsies, wound swaps, cerebrospinal fluid), only 6 were positive (catheter-related infection, $\mathrm{n}=5$; urinary tract infection, $\mathrm{n}=1$ ). Reactivation of cytomegalovirus or herpes simplex virus occurred in one and three patients, respectively. All patients had received broad-spectrum antibiotics, eight of them plus antifungals.

\footnotetext{
* Correspondence: matthieuschmidt@yahoo.fr

Medical-Surgical Intensive Care Unit, iCAN, Institute of Cardiometabolism and Nutrition, Hôpital de la Pitié-Salpêtrière, Assistance Publique-Hôpitaux de
} Paris, Paris, France

Even apart from ECMO, optimal timing, pharmacokinetics and, therefore, dosing of $\mathrm{CT}$ in patients with acute organ dysfunctions is largely unknown. Nevertheless, CT may be the only option if hematologic malignancies themselves cause organ dysfunction, especially in pulmonary involvement [6]. Nowadays, administration of CT is common practice in critically ill patients and affects every fourth ICU patient with hematologic malignancies in dedicated centers [7]. Importantly, CT does not negatively influence survival in large cohorts, even in cases of subsequent sepsis [7-9]. By clinical judgment, postponing CT was not an option in any of our five patients, of whom three are in complete remission after 13, 15 and 46 months.

As a survival benefit of veno-venous ECMO still has to be proven in patients with acute respiratory failure, thorough case-by-case evaluation is absolutely essential. 
According to our findings, the risk of nosocomial infections or CT-related issues should not lead to general exclusion of patients with hematologic malignancies from ECMO. Further research is warranted.

\section{Abbreviations}

CT: Chemotherapy; ECMO: Extracorporeal membrane oxygenation.

\section{Competing interests}

MS declares that they have no competing interests. DB reports receiving research support from Maquet Cardiovascular, including travel expenses for research meetings, as well as anticipated support for upcoming studies and compensation paid to Columbia University for research consulting. He receives no direct compensation from Maquet. He is a member of the Medical Advisory Board for ALung Technologies. Compensation is paid to Columbia University; he receives no direct compensation from ALung Technologies. AC is the primary investigator of the EOLIA trial, NCT01470703, a randomized trial of W-ECMO supported in part by MAQUET. AC has received honoraria for lectures by MAQUET.

\section{Acknowledgements}

Source of funding: MS was supported by The French Intensive Care Society (SRLF), the 'Fonds de dotation Recherche en Santé Respiratoire, 2012', the 'Collège des Enseignants de Réanimation Médicale' and the 'Fonds d'Etudes et de Recherche du Corps Médical, Assistance publique-Hôpitaux de Paris'.

\section{Published online: 15 September 2014}

\section{References}

1. Wohlfarth $P$, Ullrich R, Staudinger T, Bojic A, Robak O, Hermann A, Lubsczyk B, Worel N, Fuhrmann V, Schoder M, Funovics M, Rabitsch W, Knoebl P, Laczika K, Locker GJ, Sperr WR, Schellongowski P: Extracorporeal membrane oxygenation in adult patients with hematologic malignancies and severe acute respiratory failure. Crit Care 2014, 18:R20.

2. Schmidt M, Bréchot N, Hariri S, Guiguet M, Luyt CE, Makri R, Leprince P, Trouillet J-L, Pavie A, Chastre J, Combes A: Nosocomial infections in adult cardiogenic shock patients supported by venoarterial extracorporeal membrane oxygenation. Clin Infect Dis 2012, 55:1633-1641.

3. Aubron C, Cheng AC, Pilcher D, Leong T, Magrin G, Cooper DJ, Scheinkestel $C$, Pellegrino $\mathrm{V}$ : Infections acquired by adults who receive extracorporeal membrane oxygenation: risk factors and outcome. Infect Control Hosp Epidemiol 2013, 34:24-30.

4. Hoeper MM, Wiesner O, Hadem J, Wahl O, Suhling H, Duesberg C, Sommer W, Warnecke G, Greer M, Boenisch O, Busch M, Kielstein JT, Schneider A, Haverich A, Welte T, Kühn C: Extracorporeal membrane oxygenation instead of invasive mechanical ventilation in patients with acute respiratory distress syndrome. Intensive Care Med 2013, 39:2056-2057.

5. Shekar K, Fraser JF, Smith MT, Roberts JA: Pharmacokinetic changes in patients receiving extracorporeal membrane oxygenation. J Crit Care 2012, 27:e9-e18.

6. Moreau AS, Lengline E, Seguin A, Lemiale V, Canet E, Raffoux E, Schlemmer B, Azoulay E: Respiratory events at the earliest phase of acute myeloid leukemia. Leuk Lymphoma. in press.

7. Azoulay E, Mokart D, Pène F, Lambert J, Kouatchet A, Mayaux J, Vincent F, Nyunga M, Bruneel F, Laisne LM, Rabbat A, Lebert C, Perez P, Chaize M, Renault A, Meert AP, Benoit D, Hamidfar R, Jourdain M, Darmon M, Schlemmer B, Chevret S, Lemiale V: Outcomes of critically ill patients with hematologic malignancies: prospective multicenter data from France and Belgium - a groupe de recherche respiratoire en reanimation onco-hematologique study. J Clin Oncol 2013, 31:2810-2818.

8. Vandijck DM, Benoit DD, Depuydt PO, Offner FC, Blot SI, Van Tilborgh AK Nollet J, Steel E, Noens LA, Decruyenaere JM: Impact of recent intravenous chemotherapy on outcome in severe sepsis and septic shock patients with hematological malignancies. Intensive Care Med 2008, 34:847-855.
9. Wohlfarth P, Staudinger T, Sperr WR, Bojic A, Robak O, Hermann A, Laczika K, Carlström A, Riss K, Rabitsch W, Bojic M, Knoebl P, Locker GJ, Obiditsch M, Fuhrmann $V$, Schellongowski P: Arbeitsgruppe für hämato-onkologische Intensivmedizin der Österreichischen Gesellschaft für Internistische und Allgemeine Intensivmedizin und Notfallmedizin (ÖGIAIN): Prognostic factors, long-term survival, and outcome of cancer patients receiving chemotherapy in the intensive care unit. Ann Hematol 2014. Jul 6. [Epub ahead of print].

doi:10.1186/s13054-014-0522-0

Cite this article as: Schmidt et al:: Patients with hematologic malignancies have many reasons to die during extracorporeal membrane oxygenation. Critical Care 2014 18:522. 